\title{
Graphene-Based Polymer Nanocomposites
}

\author{
Horacio J. Salavagione, Gerardo Martínez and Gary Ellis \\ Institute of Polymer Science and Technology, Spanish National Research Council (CSIC) \\ Spain
}

\section{Introduction}

Materials science continues to occupy a central place in our lives primarily through the design and creation of new materials, and our quality of life has improved over time thanks to the discovery of new materials. Major milestones in the advancement of our society are intimately associated with materials throughout history: the stone age, bronze age, iron age, steel age (industrial revolution), silicon age and silica age (telecom revolution) all reflect the important impact materials have in our civilization, and our daily life in the 21st century depends on an unlimited variety of materials of varying degrees of sophistication. Also, since our world is dominated by a consumer market, the demands to improve our lifestyle are without limit. Materials are fundamental to the technology that adds convenience to our lives, examples being laptop computers, digital cell phones, touch screens, and so on. Therefore, the challenge of creating new, more useful and diverse materials grows with the needs of society, and the limitations for covering needs such as sustainable energy, affordable health care, personal protection, etc., are closely related to constraints in the properties of materials.

One critical aspect for achieving materials with new improved properties is imaginative molecular design, synthesis and preparation of new materials. Materials chemistry focuses on understanding the relationships between the arrangement of atoms, ions or molecules comprising a material and its overall bulk structural/physical properties. Thus, it consists in the study of the structure and properties of existing materials, the synthesis and characterization of new or improved materials, and the use of advanced computational techniques to predict structures and properties of materials that have not yet been made. Since our demands are renewed continuously and new needs emerge daily, for further progress to meet present and future requirements a thorough understanding of existing materials and the tailor-making of new functional materials must be continued with increasing vigour.

Nowadays, in the frontiers of materials technology the concept of combining various types of materials through synergy is one of the most successful approaches to achieve specific goals with the greatest efficiency in properties and cost effectiveness. In this respect, polymers are one of the most successfully exploited classes of materials due to the incredible variety of chemical structures available and their subsequent compendium of properties, along with their relatively low cost, facile processing, and their possible recyclability and applicability as sustainable materials. The area of polymer nanocomposites (PNCs) has grown to represent one of the largest classes within the scope of materials science, becoming 
a key area in nanoscience and nanotechnology offering significant potential in the development of advanced materials in numerous and diverse application areas (Ajayan et al. 2000, Thostenson et al. 2001, Ray and Okamoto 2003). Polymer nanocomposites are commonly defined as the combination of a polymer matrix and additives that have at least one dimension in the nanometre range. The additives can be one-dimensional, such as nanotubes and fibres, two-dimensional, which include layered clay minerals or graphene sheets, or three-dimensional, including spherical particles.

PNCs attract considerable interest due to the outstanding mechanical, optical, electrical, and thermal properties encountered with only a small quantity of nanofiller incorporated to the polymer matrix. This is caused by the large surface area to volume ratio of fillers when compared to micro- and macro-scale additives. The field of polymeric nanocomposites has evolved significantly from the earliest clay reinforced thermosetting resin Bakelite (Baekland 1909) developed at the beginning of the 20th century. New nanoscale materials are employed to reinforce polymers almost as soon as they have been discovered or developed, and continuing interest in the most widely used successful examples of nanofillers such as layered silicate clay-based nanocomposites and carbon nanotube-based nanocomposites have evolved more recently towards graphene-based nanocomposites.

The specific development of polymeric nanocomposites based on conventional polymers and conductive carbonaceous materials has drawn much attention as a route to obtain new materials with new structural and functional properties superior to those of the pure components and of previous nanocomposite systems with other fillers. Control of the size, shape and surface chemistry of the reinforcement materials are essential in the development of materials that can be used to produce devices, sensors and actuators based on the modulation of functional properties. At present, nanocomposites employing carbon-based reinforcement materials are dominated by carbon nanotubes (CNTs). However, the development of CNT-reinforced composites has been impeded by both their difficult dispersion in the polymer matrix and their high cost. A detailed analysis of CNTs-reinforced nanocomposites is beyond the scope of this chapter and several excellent books and reviews have been published (Ajayan et al 2000, Thostenson et al. 2001, Krueger 2010).

The discovery of graphene (Novoselov, et al 2004) and the subsequent development of graphene-based polymer nanocomposites is an important addition in the area of nanoscience, poised to play a key role in modern science and technology. Compared to carbon nanotubes, as well as its high aspect ratio and low density graphene has attracted considerable attention because of its unique and outstanding mechanical, electrical and electronic properties, which result in it being one of the most popular candidates for the development of functional and structural graphene-reinforced composites. Indeed, graphene-based PNCs is a rapidly growing area of nanoengineered materials, providing lighter weight alternatives to CNTs-based nanocomposites with additional functionality associated with nanoscale specific, value-added properties.

As clearly explained in previous chapters, graphene is an atomically thick, two-dimensional (2-D) sheet composed of $\mathrm{sp}^{2}$ carbon atoms arranged in a honeycomb structure, viewed as the building block of all other graphitic carbon allotropes of different dimensionality, such as graphite, CNTs and fullerene (Geim and Novoselov, 2007). Graphene sheets have higher surface-to-volume ratios than CNTs owing to the inaccessibility of the inside surface of the nanotubes to the polymer molecules. This makes graphene sheets potentially more favourable for altering all matrix properties-such as the mechanical, rheological and 
permeability properties, and thermal stability. Further, graphene is obtained from naturally occurring graphite implying that lighter nanocomposites can be produced at lower costs.

Tailor-made graphene-based nanocomposites which exploit the superlative properties of both graphene filler and polymer host can show enhanced performance in a large number of applications ranging from flexible packaging, semi-conductive sheets in transistors, memory devices, hydrogen storage, printable electronics, etc.

As occurred with other nanofillers, the maximum improvements in final properties can be achieved when the graphene is homogeneously dispersed in the matrix and the external load is efficiently transferred through strong filler/polymer interfacial interactions. However the nature of graphene makes it hard to disperse within the majority of polymers since it can only interact efficiently with a limited group of polymers typically containing aromatic rings. In addition, the low solubility of pristine graphene also limits its applications. In order to make graphene dispersible in - or compatible with - a variety of polymer matrices, as well as to maximize the interfacial interactions, chemical modification is generally required, introducing functional moieties that confer other properties to the pristine material.

This chapter will focus on functionalized graphene derivatives that have been employed in polymer nanocomposites obtained by solution intercalation. Although two more general methods for graphene dispersion in polymers exist, such as in-situ intercalative polymerization and melt intercalation, the area is overwhelmingly dominated by those prepared in solution. Some examples dealing with in-situ intercalative polymerization will be given, however, only a few examples of melt intercalation can be found. Whilst melt processing is one of the most important and widespread processing techniques in polymer materials production, it is generally not recommended because high-temperature mechanically driven processing can fragment the graphene sheets significantly decreasing the aspect ratio.

In spite of the fact that graphene is the youngest carbon allotrope, the exploration of its chemistry is rapidly advancing (Loh et al. 2010) and this chapter represents an updated panorama of the developments in the field of graphene based PNCs.

\section{Discussion}

\subsection{Graphite oxide (GO) and Reduced graphite oxide (r-GO)}

Graphite oxide $(\mathrm{GO})$ is chemist's principal tool to modify graphene. It is obtained from the exhaustive oxidation of graphite, and contains a range of oxygen functional groups with specific chemistry, rendering it a good candidate for further functionalization (Dreyer et al. 2010). In addition currently the most promising methods for large scale production of graphene are based on exfoliation that generates graphene oxide, and its subsequent reduction.

Today there is no unambiguous model to describe the exact structure of graphite oxide because authors from different laboratories use different preparative methods and there is no single definitive analytical technique available to characterize the material. Even though there is some controversy and debate about the structure of GO, there seems to be consensus that the carboxylic groups are mainly located at the edge, while the rest of functional groups (hydroxyl, epoxide, etc.) are located in the basal planes of the graphitic layers. For better understanding and a deeper view on the chemical structure of GO the reader can visit other chapters in this book and an interesting review by the group of Prof. R. Ruoff (Dreyer et al. 2010). 
The dispersability of GO depends on the extent of surface oxygenated groups as well as on the chosen solvent. However, it can be dispersed in a wide range of the same solvents in which the principal soluble polymers can be dissolved. Thus graphite oxide is dispersed in a solvent common to a specific polymer and then reduced to r-GO in presence of the polymer, with the aim of restoring the $\mathrm{sp}^{2}$ network. The effective interaction between functional groups in GO and those in the polymers avoid the re-stacking of the graphitic layers after the reduction step. This constitutes the first type of example we shall describe in this chapter: the use of graphite oxide without further functionalization.

Poly(vinyl alcohol) (PVA) has been one of the preferred polymers to address this strategy. The high capacity of PVA to simultaneously form both intra- and interchain hydrogen bonding makes it an interesting polymer which could interact with GO in the same way and could be used as a model for understanding the interaction of graphite oxide with other polar polymers. For example, the synthesis of PVA/r-GO nanocomposites by chemical reduction of waterdispersed graphite oxide in presence of PVA has been reported (Salavagione et al. 2009). It has been proposed that some interactions occur between the polymer and the reduced graphite oxide layers, mainly by hydrogen bonding. These interactions are responsible for a remarkable change in the thermal behaviour of the nanocomposites. In addition, the electrical properties of the nanocomposites were superior not only with respect to the parent polymer but also compared with PVA/CNT nanocomposites. They show the typical insulating-conductive percolation behaviour (Figure 1). That is, conductivity remains at very low values (10-13 to $10^{-14}$ S. $\mathrm{cm}^{-1}$ ) until a critical loading content is achieved. Then, it increases quickly by several orders of magnitude up to ca. $10^{-5} \mathrm{~S} . \mathrm{cm}^{-1}$. The percolation threshold for r-GO/PVA nanocomposites observed, between 0.5 and $1 \mathrm{wt} \%$, was one order of magnitude lower than that reported for PVA/CNTs (Shaffer et al. 1999).

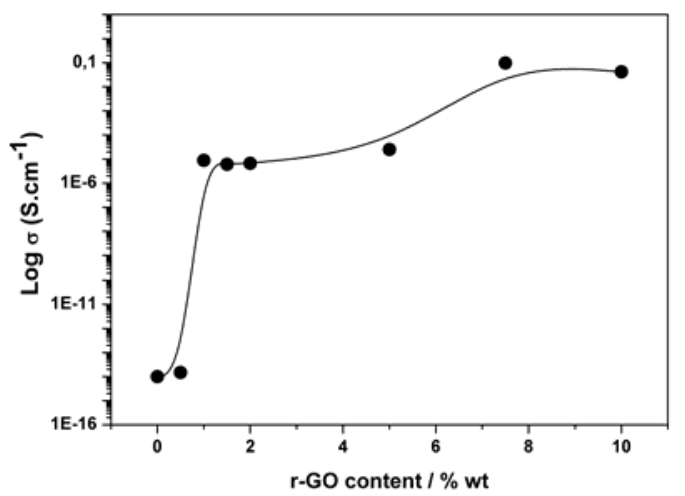

Fig. 1. Plot of the electric conductivity of PVA/RGO nanocomposites as a function of the RGO content (Reprinted with permission of The Royal Society of Chemistry, 2009).

In another example, the same procedure excluding the reduction step was employed to prepare PVA/GO nanocomposites (Liang et al. 2009). These nanocomposites showed enhanced mechanical performance due to the large aspect ratio of the graphene sheets, the molecular-level dispersion of the graphene sheets in the PVA matrix, and mainly due to strong interfacial adhesion due to hydrogen-bonding between graphene and the PVA matrix. For example, with only $0.7 \mathrm{wt} \%$ GO the tensile strength increased by $76 \%$ from 49.9 
to $87.6 \mathrm{MPa}$ and the Young's modulus increased by $62 \%$ from 2.13 to $3.45 \mathrm{G}$ Pa with respect to the parent polymer.

Recently a similar procedure using sodium dodecylbenzene sulphonate (SDBS) as a surfactant has been reported (Zhao et al. 2010). The nanocomposites were prepared by chemical reduction of GO in an aqueous solution containing PVA and the stabilizing SDBS. The final products displayed significant enhancement of mechanical properties at low graphene loading: a 150\% improvement of tensile strength and a nearly 10 times increase of Young's modulus were achieved at a graphene loading of only $1.8 \mathrm{vol} \%$. Also the value of the elongation at break decreased from $220 \%$ for the polymer to $98 \%$ for the composite with the same loading, which was attributed to a large aspect ratio and the interaction between graphene and the matrix, which restricts the movement of the polymer chains.

Another remarkable study reported the fabrication of graphene-polymer nanocomposites with three-dimensional architectures (Vickery et al. 2009), where template-directed methods were employed to obtain higher-order architectures. Sponge-like macroporous scaffolds were generated by ice-segregation-induced self-assembly (ISISA) by freezing aqueous dispersions that contained homogeneous mixtures of polystyrene sulfonate-stabilized graphene sheets (PSS-G) and PVA (Figure 2).

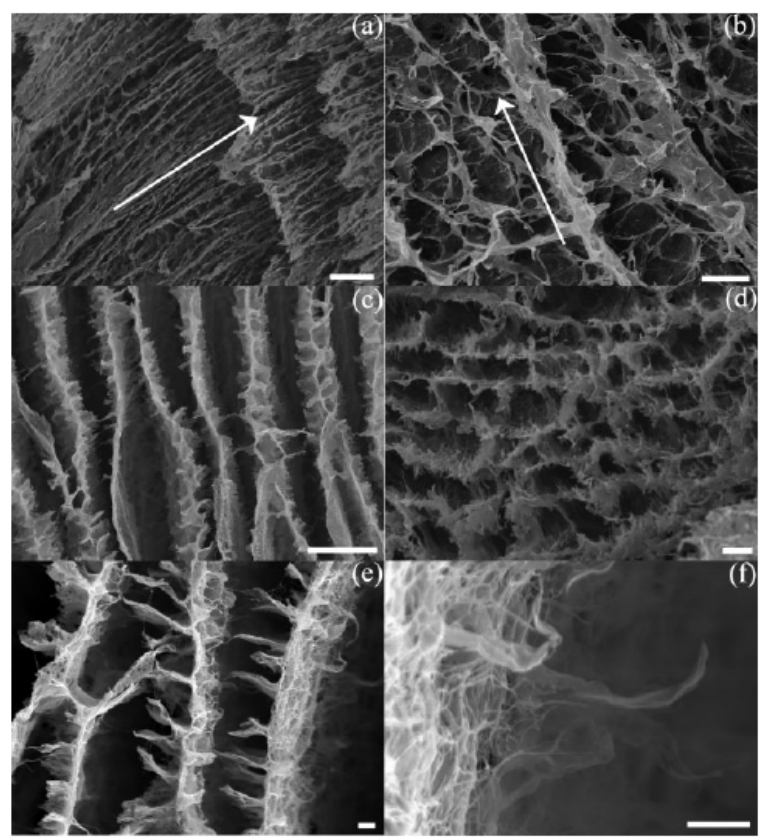

Fig. 2. SEM images of (a),(b) longitudinal sections, and (c),(d) cross sections of a PSS-G/PVA freeze-dried monolith (1:10 wt. ratio). Arrows in (a) and (b) indicate direction of freezing. Images (a),(c) show a layered structure, (b),(d) show a macroporous architecture. Image (e) is a higher-magnification image of the layered structure showing interlamellar cross links, and (f) shows an image of a single wall with loosely packed graphene sheets. Scale bars: 10 $\mu \mathrm{m}$ for (a),(c), and (d); $5 \mu \mathrm{m}$ for (b); and $1 \mu \mathrm{m}$ for (e) and (f). (Reprinted with permission of Willey-VCH, 2009). 
In addition, hollow micrometer-sized PSS-G spheres or PSS-G coated polymer microparticles were prepared by the aqueous deposition of negatively charged PSS-G dispersions on the positively charged polymer bead surfaces (Figure 3).

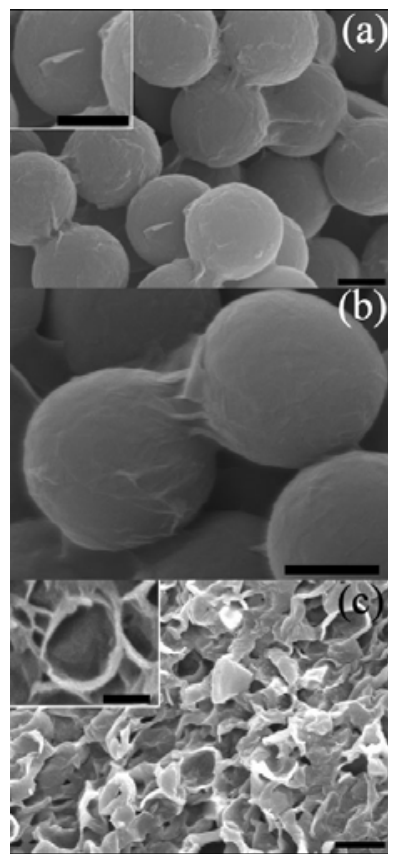

Fig. 3. SEM images of PSS-G-coated PAH-functionalized polystyrene beads: (a) Coated beads with surface textures. The inset shows the curled edge of an adsorbed PSS-G sheet, (b) High-magnification image showing overlapping PSS-G sheets on neighbouring beads, and (c) Sample after treatment with toluene showing aggregated film of deflated and fractured hollow graphene microspheres. The inset shows a single deflated hollow graphene microsphere. Scale bars: $(\mathrm{a}),(\mathrm{b})=500 \mathrm{~nm},(\mathrm{c})=1 \mu \mathrm{m}$. (Reprinted with permission of WilleyVCH, 2009).

Finally, GO/PVA hydrogel nanocomposites have been recently prepared (Bai et al. 2010). The formation of the hydrogels relied on the assembly of GO sheets and the cross-linking effect of PVA chains. The GO/PVA hydrogels exhibited $\mathrm{pH}$-induced gel-sol transition and they were tested for loading and selectively releasing drugs at physiological $\mathrm{pH}$.

Although here we only give a few representative examples on PVA/GO nanocomposites, a wide number of other studies can be found in the literature.

GO has also been employed in epoxy nanocomposites. In the first example, the materials were prepared by mixing adequate amounts of a GO aqueous solution with epoxy resin (Yang et al. 2009). Significant improvements in mechanical properties were achieved for the graphene oxide/epoxy resin for a $0.0375 \mathrm{wt} \%$ loading of chemically converted graphene oxide sheets, with an increase of $48.3 \%$ and $1185.2 \%$ in compressive failure strength and toughness, respectively. 
In another study, GO was thermally reduced before mixing with the epoxy resin (Yu et al. 2007). Thermal conductivity measurements indicated that four layer GO, with a thickness of ca. $2 \mathrm{~nm}$ acts as a very efficient filler for epoxy composites. When embedded in an epoxy matrix, these graphite nanoplatelets provide a thermal conductivity enhancement of more than $3000 \%$ at a loading of $25 \mathrm{vol} \%$, and a thermal conductivity $\mathrm{k}=6.44 \mathrm{~W} / \mathrm{mK}$, which far surpasses the performance of conventional fillers that require loadings of around $70 \mathrm{vol} \%$ to achieve these values. The thermal conductivity using graphite nanoplatelets was higher than that using other carbon allotropes (Figure 4). This improvement in the properties was ascribed to the favourable combination of the high aspect ratio, two-dimensional geometry, stiffness, and low thermal interface resistance of the graphene nanoplatelets.

The above strategy relies on the fact that thermally or chemically reduced graphite oxide retains specific amounts of oxygenated groups, primarily as carboxylic moieties in the edge planes. This material is known as functionalized graphene sheets (FGS) (Li et al. 2008). Similarly, FGS was used as filler for poly(methyl methacrylate) (PMMA)] (Ramanathan, et al. 2007). The authors concluded that the reduced particle size, high surface area, and increased surface roughness significantly alter the filler/polymer interface enhancing the mechanical, thermal and electrical properties of the polymer matrix. In addition, an unprecedented shift in the glass transition temperature of over $40{ }^{\circ} \mathrm{C}$ was obtained for poly(acrylonitrile) (PAN) with $1 \mathrm{wt} \%$ of functionalized graphene sheet, and with only 0.05 $\mathrm{wt} \%$ there is still an improvement of nearly $30{ }^{\circ} \mathrm{C}$. Modulus, ultimate strength and thermal stability followed a similar trend, with values for functionalized graphene sheet-PMMA composites rivalling those for single-walled carbon nanotube-PMMA composites (Ramanathan et al. 2008).

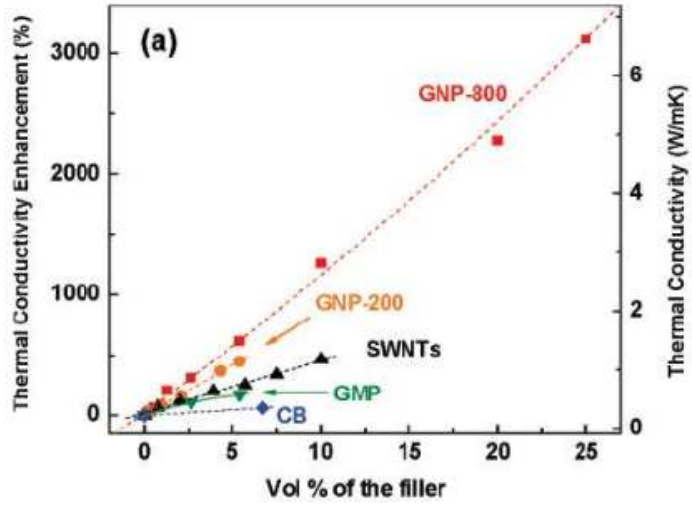

Fig. 4. Thermal conductivity enhancement of epoxy-based composites at $30^{\circ} \mathrm{C}$, using various graphitic fillers: graphitic microparticles (GMP), graphite nanoplatelets exfoliated at $200{ }^{\circ} \mathrm{C}$ (GNP-200) and $800^{\circ} \mathrm{C}$ (GNP- 800), carbon black (CB), and purified SWNTs

(Reprinted with permission of The American Chemical Society, 2007)

In another interesting example graphene nanosheets in the form of chemically reduced GO have been prepared in organic media (Villar-Rodil et al. 2009). The ability to prepare graphene dispersions in organic media facilitated their combination with polymers, such as PAN and PMMA, to yield homogeneous composites. Copolymers have been also employed to prepare nanocomposites with graphene. For instance, a stable aqueous graphene sheet 
dispersion was prepared via the chemical reduction of exfoliated GO in the presence of a pluronic copolymer (poly-(ethylene oxide)-block-poly(propylene oxide)-block-poly(ethylene oxide) triblock copolymer, PEO-b-PPO-b-PEO) (Zu and Han, 2009). Using this system the hydrophobic PPO segments bind to the surface of graphene via a hydrophobic effect, whereas the hydrophilic PEO chains extend into the water. The authors used the pluronic-graphene nanocomposites to prepare supramolecular hydrogels of the resulting graphene dispersion upon addition of R-cyclodextrin (R-CD) since the PEO chain can penetrate into the R-CD cavity. Potential applications in drug delivery are envisaged.

On the other hand, nanocomposites of r-GO with intrinsically conductive polymers have been reported (Zhao et al. 2009). A thin film of GO was deposited on indium tin oxide (ITO) electrodes, thermally reduced and covered with a layer of polyaniline (PANI). The PANI on graphene exhibited much higher electrochemical stability than PANI-ITO in aqueous acidic electrolytes and the performance of the electrochromic devices with graphene electrodes exhibited only slight decrease upon voltage switching while that of the devices with conventional ITO electrodes decreased considerably (Figure 5).
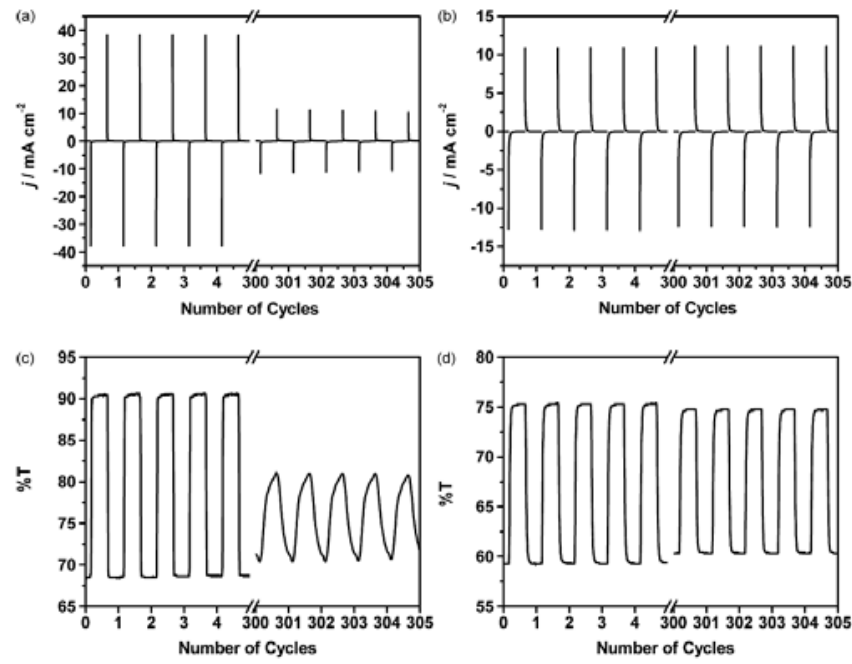

Fig. 5. Chronoamperometry ( $\mathrm{a}$ and b) and transmittance curves at $700 \mathrm{~nm}$ (c and d) of the PANI-ITO ( $a$ and c) and PANI-Graphene ( $b$ and d) electrodes in 1 mol. $\mathrm{L}^{-1} \mathrm{H}_{2} \mathrm{SO}_{4}$ for the first 5 and the 301st-305th cycles when an anodic potential was switched between $-0.1 \mathrm{~V}$ and $0.5 \mathrm{~V}$ vs. $\mathrm{Ag} / \mathrm{AgCl}$ for $10 \mathrm{~s}$ at each step (Reprinted with permission of Elsevier, 2009).

Also r-GO/polyelectrolyte nanocomposites have been prepared (Ansari et al. 2010). In this case well-dispersed nanocomposites with highly aligned graphene nanosheets in a polyelectrolyte (Nafion) matrix were described. By adapting experimental protocols originally developed for clay nanocomposites, highly oriented GO-Nafion nanocomposites were prepared by casting from an aqueous suspensión. Subsequent exposure of the GONafion nanocomposites to hydrazine reduced the GO platelets in-situ producing wellaligned graphene-Nafion nanocomposites. The $\alpha$ relaxation of Nafion shifted to higher temperatures in the nanocomposites by as much as $50{ }^{\circ} \mathrm{C}$ in the sample containing $7 \mathrm{wt} \%$ of GO. The modulus of the same sample was about a factor of two higher compared to that for 
neat Nafion. Both of these effects was directly related to the molecular confinement in the vicinity of the organic/inorganic interface that drastically hinders the mobility of the polymer chains. Finally, after reduction with hydrazine, a conductivity value of $1.3 \mathrm{~S} . \mathrm{m}^{-1}$ was observed.

Ionic liquid polymers have also been employed to stabilize graphene dispersions (Kim et al. 2010). Briefly, the ionic liquid polymers were dissolved in water and added to an aqueous GO dispersion. This mixture was then reduced with hydrazine monohydrate to obtain r-GO sheets decorated with ionic liquid polymers that were well-dispersed in the aqueous phase and stable to chemical reduction. The authors demonstrated that hydrophilic-tohydrophobic reversible switching of graphene sheets was possible by simply exchanging the anions associated with polymeric ionic liquids (PIL)(Figure 6).

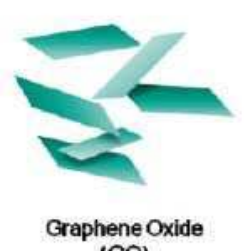

(GO)

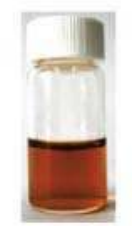

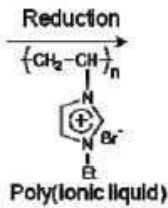

Poly(ionic liquid)
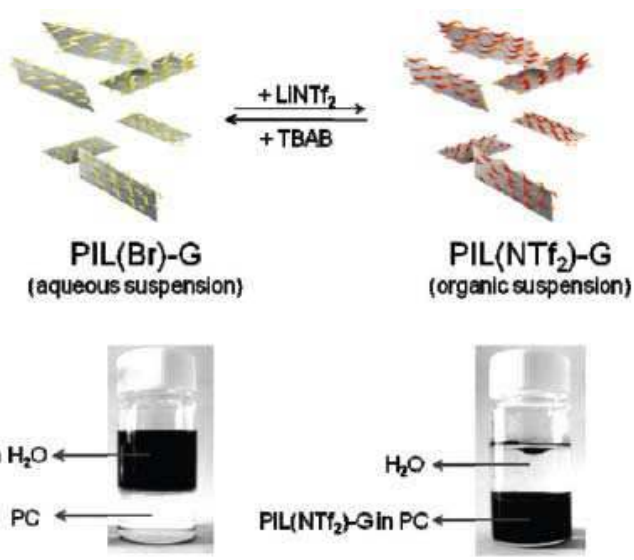

Fig. 6. Schematic illustration of synthetic process for the PIL-modified graphene sheets.

(Reprinted with permission of American Chemical Society, 2010).

Finally, graphene-based nanocomposites have also been produced by in-situ intercalative polymerization. GO was employed in the polymerization of PVA (Liu et a 2000), PMMA (Jang et al. 2009), epoxy (Wang et al. 2009), poly(arylene disulphide) (Du et al.2005), and PANI (Wang et al. 2009; Zhang et al. 2010), while FGS were employed in the polymerization of silicone foams (Verdejo, et al. 2008) and poly(urethane) (Lee et al. 2009).

\subsection{Functionalized graphite oxide (f-GO)}

The reactive groups in GO offer the possibility of further modification rendering a more versatile filler for polymer nanocomposites. In principle, the chemistry of carboxylic, hydroxyl and epoxy groups can be extended to GO.

A complete study on the functionalization of GO with a wide number of organic isocyanates has been reported (Stankovich et al. 2006) (Figure 7). Exfoliation in polar aprotic solvents of isocyanate-treated GOs (iGOs) produced functionalized graphene oxide nanoplatelets that form stable colloidal dispersions. The authors concluded that the isocyanate treatment results in the derivitization of the carboxyl and hydroxyl groups on GO via the formation of 
amides and carbamate esters, respectively. They proposed that the extent of functionalization can be controlled either by the reactivity of the isocyanate or the reaction time, and GO nanoplatelets with different surface functional groups have been prepared using this methodology.

The iGOs ensure molecular-level dispersion of individual, chemically modified graphene sheets within polymer hosts such as polystyrene (PS) (Stankovick et al. 2006). Briefly, PS was added to stable dispersions of phenyl isocyanate-treated GO materials and dissolved by stirring. Reduction of the dispersed material was accomplished with dimethylhydrazine at $80{ }^{\circ} \mathrm{C}$ for $24 \mathrm{~h}$. The resulting PS-graphene nanocomposite displayed good electrical conductivity with a percolation threshold of $0.1 \mathrm{vol} . \%$. The authors attributed this striking result to the extremely high aspect ratio of the graphene sheets and their excellent homogeneous dispersion in the PS matrix. It is probable that individual graphene sheets interact with the aromatic matrix through $\pi-\pi$ interactions avoiding aggregation or restacking after the reduction step.

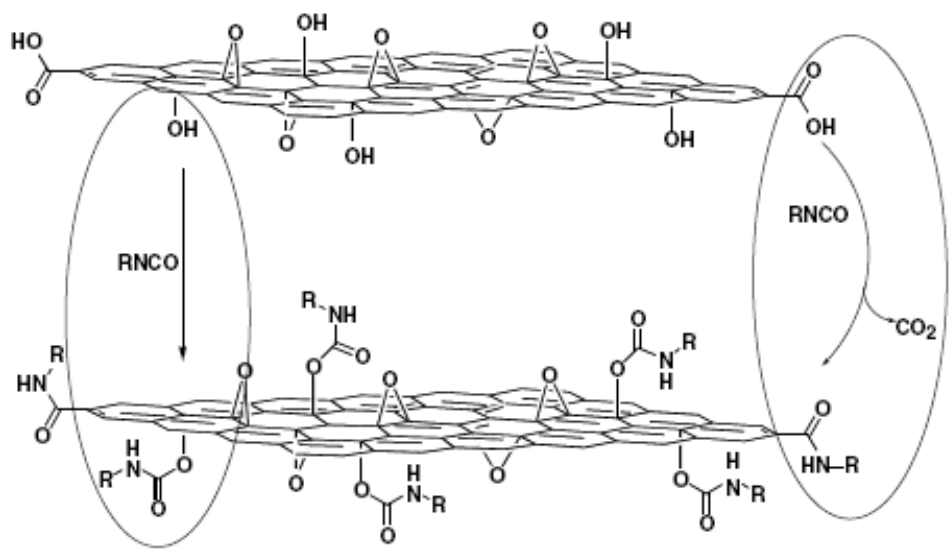

Fig. 7. Proposed reactions during isocyanate treatment of GO. Organic isocyanates react with hydroxyl (left) and carboxyl groups (right) of GO sheets to form carbamate and amide functionalities, respectively (Reprinted with permission of Elsevier, 2006).

In another study, r-GO-PS nanocomposites prepared using the above procedures were tested for electronic devices (Figure 8) (Eda et al. 2009). The authors demonstrated ambipolar field effect characteristics in transistors made from graphene-based composite thin films, and suggested that transport takes place via percolation between the functionalized graphene sheets in the insulating polymer matrix. Further, they showed that the highest mobility values were obtained in devices fabricated using the largest sized functionalized graphene sheets.

The same procedure was carried out to prepare r-GO/PS nanocomposites for field emission (Eda et al. 2008). Field emission from graphene is challenging because current deposition methods produce sheets that lie flat on the substrate surface, resulting in limited field enhancement. The authors described a simple and general solution-based approach for the deposition of field emitting graphene/polymer composite thin films, where angular orientation of the graphene sheets with respect to the substrate surface lead to field emission at low threshold fields in the order of $4 \mathrm{~V} \cdot \mu \mathrm{m}^{-1}$ 
iGOs have also been used as reinforcements in thermoplastic polyurethane (Kim et al. 2010). An almost 10 -fold increase in tensile stiffness and $90 \%$ decrease in nitrogen permeation were observed in thermoplastic polyurethane (TPU) with only $3 \mathrm{wt}$. \% iGO, and was related to the high aspect ratio of exfoliated platelets. By real- and reciprocal- space morphological characterization the authors determined that thin exfoliated sheets can be more effectively distributed in the polymer matrix by solvent-based blending techniques than by melt processing.

Similarly iGOs together with sulphonated graphene and r-GO were used in TPU nanocomposites (Liang et al. 2009). Especially interesting were the results on sulphonatedgraphene/polyurethane nanocomposites showing excellent light-triggered actuation with significantly enhanced mechanical properties. Actuators with 1 wt \% of sulphonated functionalized graphene sheets exhibited repeatable infrared triggered actuation performance with remarkable levels of contraction able to lift a $21.6 \mathrm{~g}$ weight $3.1 \mathrm{~cm}$ with $0.21 \mathrm{~N}$ of force on exposure to infrared light. Furthermore, a dramatic improvement in mechanical properties was also obtained for the graphene nanocomposites with a homogeneous dispersion. As the concentration of -sulphonated -graphene increased, its nanocomposites showed significantly enhanced mechanical properties, i.e. the Young's modulus increased by $120 \%$ at only $1 \mathrm{wt}$. \% loading. Moreover, through a comparative study of three kinds of graphene materials, it was found that this infrared-triggered actuation property was mainly dependent on the integrity of the aromatic network of graphene and on its level of dispersion within the matrix.

\section{(a)}

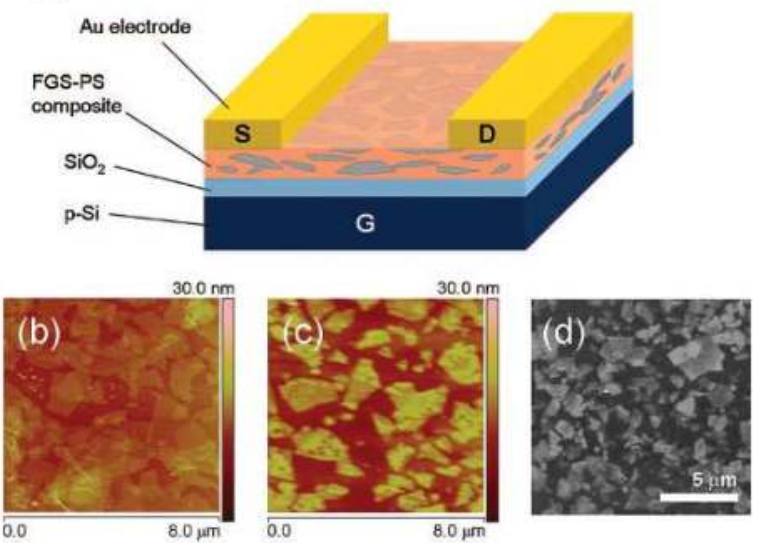

Fig. 8. (a) Schematic of functionalized graphene sheets-PS composite thin film field effect devices. Atomic force microscopies of (b) phenyl-isocyanate treated GO and (c) functionalized graphene sheets-PS composite thin films. (d) SEM of typical as-deposited functionalized graphene sheets-PS composite thin films. Contrast can be seen between conductive functionalized graphene sheets (light) and insulating PS matrix (dark) (Reprinted with permission of The American Chemical Society, 2009).

GO has also been functionalized to synthesize a polymerization-initiator covalently bonded to the GO surface. PS-graphene nanocomposites have also been prepared by grafting the polymer from an initiator-modified graphene (Fang et al. 2009). In this case the initiator molecules were covalently bonded to the graphene surface via a diazonium addition reaction 
and the subsequent atom transfer radical polymerization (ATRP) linked the PS chains. Briefly, $\mathrm{r}-\mathrm{GO}$ was treated with 2-(4-aminophenyl) ethanol and isoamyl nitrite at $80{ }^{\circ} \mathrm{C}$ (diazonium functionalization) (Figure 9). This modified r-GO was then reacted with 2-bromopropionyl bromide and the resulting product used as the initiator for styrene polymerization. The prominent confinement effect arising from the incorporation of nanosheets resulted in a $15^{\circ} \mathrm{C}$ increase in the glass transition temperature of PS compared to that of the pure polymer. The resulting PS nanocomposites with $0.9 \mathrm{wt} \%$ graphene nanosheets showed around $70 \%$ and $57 \%$ increases in tensile strength and Young's modulus, respectively.

PS-grafted graphene has been employed as a filler in PS nanocomposites (Fang et al. 2010). Specific amounts of PS-grafted graphene were dispersed in toluene and mixed with the pristine polymer, and nanocomposite films were prepared by drop-casting. The nanocomposites showed better thermal conductivity than the parent polymer. For a nanocomposite containing only $2 \mathrm{wt} \%$ of graphene the thermal conductivity at $35{ }^{\circ} \mathrm{C}$ increased from $0.18 \mathrm{~W} \mathrm{~m}^{-1} \mathrm{~K}$ for PS to $0.413 \mathrm{~W} \mathrm{~m}^{-1} \mathrm{~K}$, higher than that obtained for PS-single walled nanotubes nanocomposites with a $5 \mathrm{wt} \%$ loading. Again the higher aspect ratio of graphene emerges as the origin of these improvements. Furthermore, effective polymer/filler interfacial interactions play a key role since a lower degree of improvement in the thermal conductivity was obtained for graphite-filled nanocomposites.

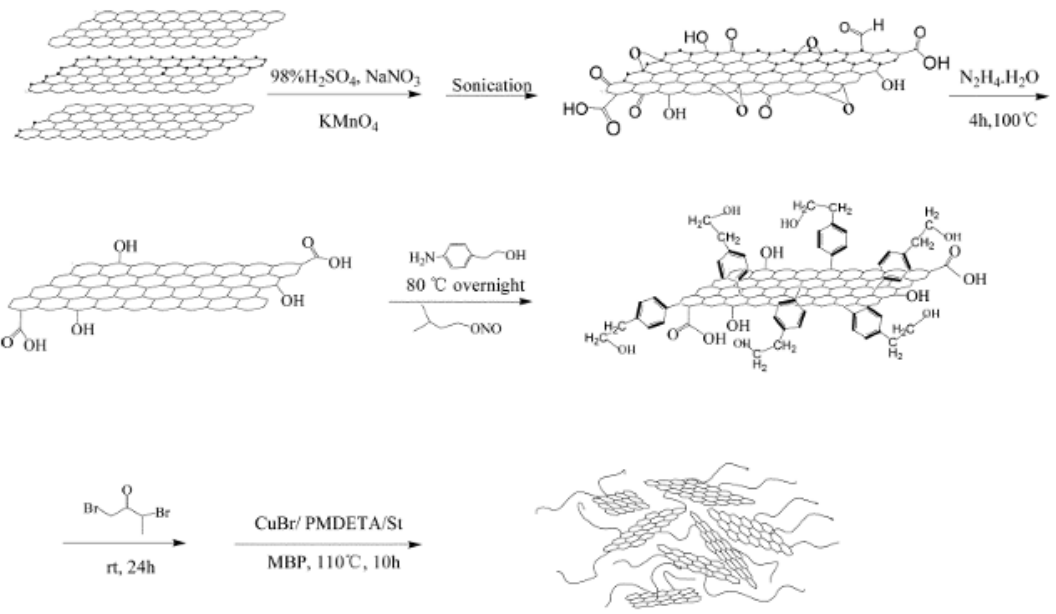

Fig. 9. Synthesis route of polystyrene-functionalized graphene nanosheets (Reprinted with permission of The Royal Society of Chemistry, 2009).

Although PS and PU dominated this section there are also interesting examples using other polymers. Polypropylene (PP) has been grafted from surface modified GO (Huang et al. 2010). Briefly, GO was modified to give a GO-supported Ziegler-Natta catalyst, and subsequent polymerization of propylene led to the in situ formation of a PP matrix accompanied by nanoscale exfoliation of GO, and consequently its gradual dispersion. Morphological examination of the PP/GO nanocomposites obtained by transmission electron microscopy (TEM) and scanning electron microscopy (SEM) demonstrated effective dispersion at the nanoscale of GO in the PP matrix. In addition, the GO/PP nanocomposites were demonstrated to be electrically conductive. 
The ATRP method has also been employed to graft poly(tert-butyl acrylate) (PtBA) from GO (Li et al. 2010). The GO was reacted with trichloro(4-chloromethylphenyl) silane to prepare the ATRP initiator-coupled GO nanosheets. The modified-GO particles were then used as the initiator in the polymerization of PtBA to give GO nanosheets with covalently grafted PtBA. The grafted hydrophobic polymer brushes obtained produed a substantial enhancement of GO solubility in organic solvents, and the GO-g-PtBA nanosheets formed a stable dispersion in toluene. The functionalized GO nanosheets were successfully integrated into an electroactive polymer matrix and subsequently a composite material based on a thin film of poly(3-hexylthiophene) (P3HT) containing $5 \mathrm{wt} \%$ GO-g-PtBA in an Al/GO-g$\mathrm{P} t \mathrm{BA}+\mathrm{P} 3 \mathrm{HT} /$ indium tin oxide (ITO) sandwich structure, where bistable electrical conductivity switching behavior and a nonvolatile electronic memory effect were observed. Finally, water-dispersible GO-g-poly(acrylic acid) (PAA) nanosheets were prepared by hydrolysis, allowing gold nanoparticle-decorated GO-g-PAA nanofilms to be prepared from aqueous dispersions (Figure 10).
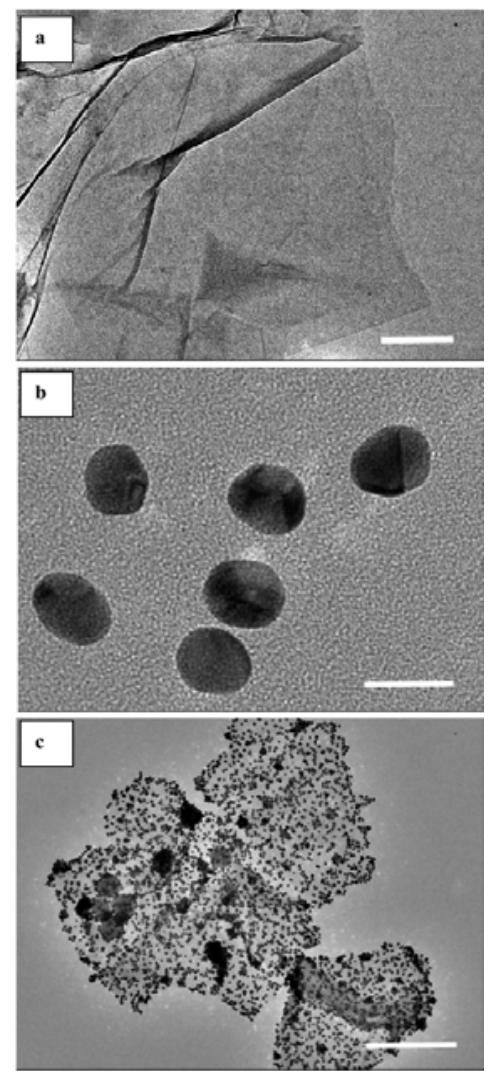

Fig. 10. TEM images of (a) GO-g-PAA nanosheets, (b) Au NPs of $18 \mathrm{~nm}$ in diameter and (c) GO-g-PAA nanosheets decorated with $18 \mathrm{~nm}$ Au NPs processed from aqueous dispersions. The respective scale bars for a, b, and c are 200, 20, and $500 \mathrm{~nm}$ (Reprinted with permission of The American Chemical Society, 2010). 
Finally, fibres of poly(vinyl acetate) (PVAc) with GO and functionalized GO, which find application as light absorbers in ultrafast photonics, were prepared by electrospinning (Bao et al. 2010). The authors used GO and three types of functionalized GO as fillers. Firstly, GO was non covalently modified with a poly[(m-phenylenevinylene)-co-(2,5-dioctoxy-pphenylenevinylene)], denominated PPV-GO. In the second example, GO was non-covalently modified with 1-pyrenebutanoic acid, succinimidyl ester and reduced with hydrazine, giving a stable r-GO dispersion (denominated G-PBASE). Eventually, r-GO was covalently modified by diazonium coupling followed by the Heck reaction to give a dye-covalent modified graphene (called G-dye). The author reported improvements in the mechanical, thermal, and optical properties of PVAc. G-PBASE and G-dye enhanced the Young's modulus, and the ultimate strength increases by $102 \%$ from 6.13 to $12.39 \mathrm{MPa}$ with only $0.07 \mathrm{wt} \%$ of G-PBASE. The authors attributed this enhancement to the good molecular-level dispersion of G-PBASE and G-dye in the PVAc matrix. The oxygen atoms in G-PBASE and the pyridinium nitrogen in Gdye provide hydrogen bonding interactions with the PVAc chains. Regarding the optical properties the graphene-based nanocomposites displayed enhanced absorbance in the region typically employed for telecommunications (around $1550 \mathrm{~nm}$ ) compared to the parent PVAc, making it a promising candidate as saturable absorber with wideband tuneable absorption and an efficient photonic material for generating ultrashort pulses in fiber lasers.

\subsection{Polymer-covalent functionalization of graphitic layers}

Usually to achieve stable dispersions of graphene and control of the microstructure of nanocomposites, polymer covalent-functionalization of graphene is necessary. The direct modification of graphene laminates with polymer matrices by using the oxygenated groups in GO represents an interesting strategy. Thus, polymers with adequate functional groups can be covalently linked to graphene sheets. This issue refers to previously prepared polymers reacting with GO or graphene, and different procedures described previously involving the polymer grafting from initiator-modified graphene.

The covalent attachment of graphene to polymer chains can generate both positive and negative effects in the final properties. The fixation of graphene can limit the conductivity, increasing the percolation threshold. However, this confinement can also significantly improve other properties such as the mechanical properties.

As an example, soluble graphene covalently functionalized with PVA has been synthesized by a simple esterification reaction of carboxylic groups in GO (Salavagione et al. 2009). The esterification reaction of GO and PVA was undertaken in dimethylsulfoxide (DMSO) using a typical catalytic system composed of $\mathrm{N}, \mathrm{N}$-dicyclohexylcarbodiimide (DCC) and 4dimethylaminopyridine (DMAP). The product was soluble in water and DMSO as was the parent PVA. Surprising results were obtained by ${ }^{1} \mathrm{H}$ NMR in the hydroxyl proton resonances which are resolvable in terms of configurational sequences, providing important information on the reaction mechanism. Since hydrogen bonding leads to downfield shifts, the chemical shifts of hydroxyl sequences resonances increase when passing from iso (4.7 $\mathrm{ppm})$ to hetero $(4.5 \mathrm{ppm})$ and from hetero to syndio $(4.2 \mathrm{ppm})$ triads. By a simple inspection of the evolution of the ${ }^{1} \mathrm{H}$ spectrum, an increase in the syndiotactic signal to the detriment of the isotactic signal was seen for the esterified product, suggesting that the esterification reaction occurs at the isotactic configuration. Surprisingly, a new signal at $4.2 \mathrm{ppm}$ upfield, very close to the syndiotactcic triads of unmodified PVA, was clearly observed in spite of the low degree of esterification. This signal can be related to hydroxyl protons next to 
acetate groups as reported for the esterification of PVA. The authors concluded that the esterification of PVA with GO proceeds through a stereoselective mechanism, which is striking regarding the incorporation of huge graphitic laminates into free-voids of the polymer. The esterified polymer showed dramatic changes in the thermal and crystalline parameters as well as in the thermal stability (Figure 11). It was observed that the melting temperature $\left(\mathrm{T}_{\mathrm{m}}\right)$ and the melting enthalpy $\left(\Delta \mathrm{H}_{\mathrm{m}}\right)$ were dramatically influenced by the presence of the graphitic layers. In the modified products the melting peaks disappeared, and the semicrystalline PVA $\left(X_{c}=0.51\right)$ became totally amorphous, supporting the existence of covalent linkages between the PVA and the graphene laminates. In addition, the mobility of the polymer chains was strongly affected. The dramatic shift in $\mathrm{T}_{\mathrm{g}}$ of $35^{\circ} \mathrm{C}$ for the esterified polymer is particularly striking, and was similar to the best available data obtained for polymer composites using individual functionalized graphene sheets (FGS) as fillers at the same composition, and the thermal stability was significantly improved. Finally, the immobilized GO laminates were reduced with hydrazine in aqueous medium to give water soluble r-GO covalently bound to the polymer matrix.

This approach has also been extended to the covalent bonding of graphene to a conveniently modified poly(vinyl chloride) (PVC) (Salavagione et al. 2011). Here graphene soluble in common organic solvents was prepared by covalent attachment of a PVC derivative, resembling earlier work using multi walled carbon nanotubes (Salavagione et al. 2010). Dynamic mechanical measurements revealed a significant increase in the storage modulus (E') of the GO-PVC with respect to the parent PVC. The evolution of $\tan \delta$ (ratio of the loss to storage modulus) as a function of temperature showed that all relaxation peaks broadened and shifted to higher temperature. This indicated that GO-fillers efficiently restrict the mobility of the PVC chains thereby increasing the stiffness of the matrix, which was also reflected in higher transition temperatures.
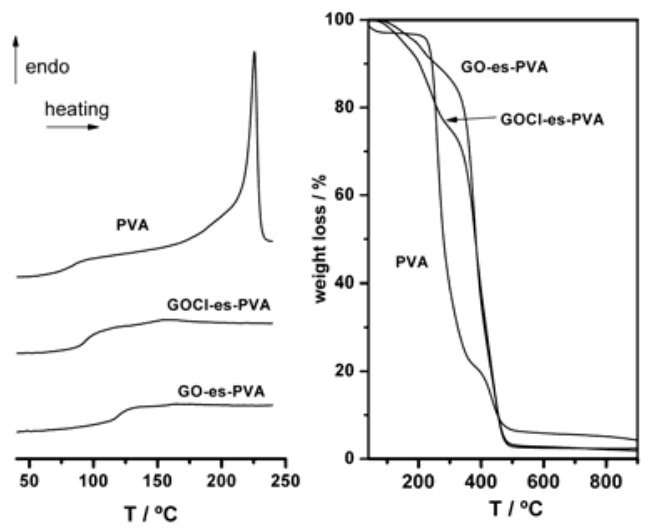

Fig. 11. Thermal behaviour of PVA, and its product of esterification with GO and thionyl chloride treated GO: DSC heating scans at $10^{\circ} \mathrm{C} \cdot \mathrm{min}^{-1}$ (left) and thermogravimetric curves (right) (Reprinted with permission of The American Chemical Society, 2009).

Although the initial focus of the graphene community is on the wonderful electronic properties of graphene, the optical applications of graphene composites may emerge in the market sooner since the optical properties can be also tuned with polymers linked to 
graphite oxide. The photoluminescence properties of GO have been employed for cellular imaging (Sun et al. 2008). GO was modified with an amine-terminated polyethylene glycol using $N$-(3-dimethylaminopropyl- $N$ '-ethylcarbodiimide) hydrochloride catalyst. The modified GO sheets were found to be soluble in buffers and serum without agglomeration and displayed photoluminescence in both the visible and infrared regions. The intrinsic photoluminescence of this material was used for live cell imaging in the near-infrared (NIR). In addition, this study demonstrated that simple physisorption via $\pi-\pi$ stacking can be used for loading doxorubicin, a widely used cancer drug onto functionalized GO with antibodies for the selective killing of cancer cells in vitro.

In another work toluene-2,4- diisocynate-modified GO was used to prepare a new soluble donor-acceptor type poly( $N$-vinylcarbazole)-covalently functionalized graphene oxide (GOPVK) (Zhang et al. 2010). The intensity of the emission band of GO-PVK at $437 \mathrm{~nm}$ was slightly quenched when compared with that of S-1-Dodecyl-S'-(a, $\mathrm{a}^{\prime}$-dimethyl- $\alpha^{\prime \prime}$ aceticacid) trithio carbonate (DDAT)-PVK, suggesting intramolecular quenching from PVK to GO. Such intramolecular quenching processes may involve energy and electron transfer between the excited singlet states of the PVK moiety and the GO moiety.

\subsection{Non-covalent functionalization}

Other alternative procedures lie in non-covalent modification. Non-covalent functionalization is preferable for solubilisation, because it enables attachment of molecules through $\pi-\pi$ stacking or hydrophobic (van der Waals) interactions, preserving the intrinsic electronic properties of graphene. The advantage is that this does not disrupt the extended $\pi$ conjugation, unlike covalent functionalization which creates defects on the graphene sheet. Pyrene derivatives have a strong affinity with the basal plane of graphene via $\pi-\pi$ interaction and this helps to stabilize graphene in aqueous solutions ( $\mathrm{Xu}$ et al. 2008). Graphene has been modified with pyrene-terminated polymers, and $\mathrm{pH}$ sensitive graphene-polymer composites have been prepared by the non-covalent modification of graphene basal planes with pyrene-terminated poly(2-N,N'-(dimethyl amino ethyl acrylate) (PDMAEA) and PAA (Liu et al. 2010). The graphene-polymer composites were found to demonstrate phase transfer behaviour between aqueous and organic media at different $\mathrm{pH}$ values. Selfassembly of the two oppositely charged graphene-polymer composites generated layer-bylayer (LbL) structures (Figure 12). SEM images show that most graphene polymer nanosheets are flat after self-assembly and the LbL structure was clearly observed. Selfassembly, monitored with a quartz crystal microbalance (QCM), showed that when the negatively charged graphene-PAA composites and the positively charged graphenePDAMEA suspensions were injected consecutively, a dramatic decrease in frequency was observed, demonstrating self-limiting assembly in intervals of around $20 \mathrm{~min}$.

In another study stable dispersions of graphene in organic solvents were achieved by noncovalent functionalization of graphene with amine-terminated polymers (Choi et al. 2010). To obtain a stable dispersion in the evaluated non-solvents, amine-terminated PS was noncovalently functionalized to graphene, while graphene sheets were phase transferred via sonication from the aqueous phase to the organic non-solvent phase, including the amineterminated polymers (Figure 13). Briefly, end-functionalized PS was dissolved in organic solvents (dichloromethane, o-xylene, benzene, and hexane) and the organic polymer solution was added to the vial containing an aqueous dispersion of reduced graphene. Then the vial including phase-separated organic and aqueous phases was subjected to sonication 
(a)

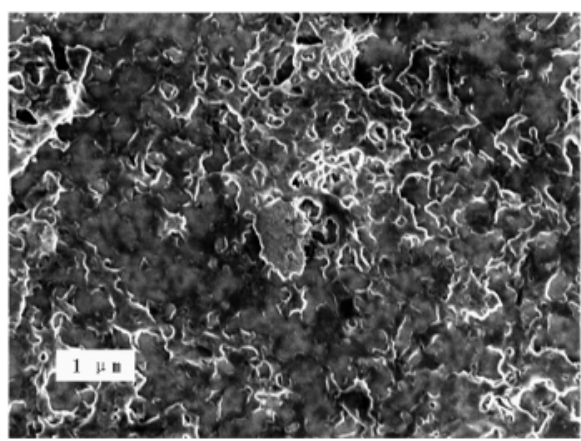

(b)

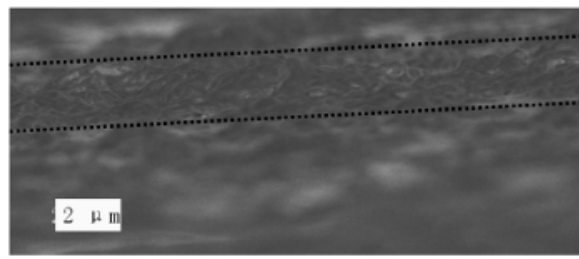

(c)

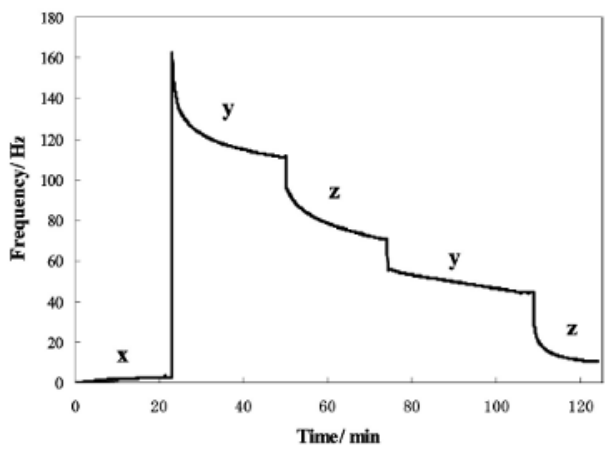

Fig. 12. High-resolution SEM images of LbL self-assembled graphene composites of PDMAEA and PAA from six self-assembly steps: (a) normal and (b) section view. (c) Quartz crystal microbalance monitorization of layer-by-layer self-assembly of positive charged (graphene-PDAMEA) and negatively charged (graphene-PAA) composites. $x$ represents the immobilization of cystamine on gold coated crystal, $y$ the self-assembly of negatively charged graphene-PAA, and $z$ the self-assembly of positive charged graphene-PDAMEA (Reprinted with permission of The American Chemical Society, 2009).

to produce the non-covalent functionalization and phase transfer of graphene. In Figure 13 the dark phase corresponds to the aqueous dispersion of reduced graphene and the transparent phase corresponds to amine-terminated PS. After sonication the reduced graphene was transferred from aqueous to organic phase via non covalent (ionic) interaction between the protonated terminal amine groups $\left(\mathrm{NH}_{3}{ }^{+}\right)$of amine-terminated PS and the remaining carboxylate groups (COO-) of reduced graphene. After phase transfer, the Raman G band of reduced graphene markedly shifted from $1589 \mathrm{~cm}^{-1}$ to $1596 \mathrm{~cm}^{-1}$ indicating improved exfoliation of the graphene layers, as occurred with GO. 
(a)

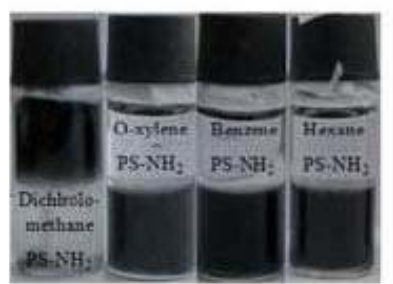

(b)

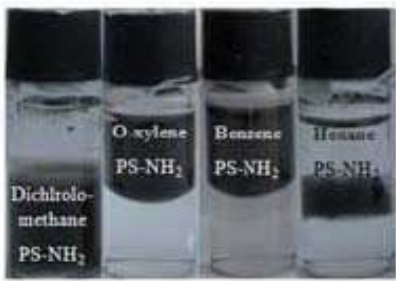

(c)
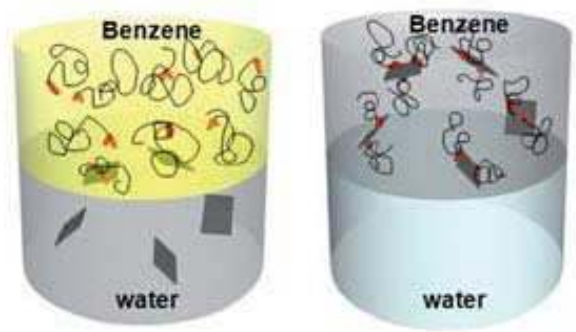

A Amine terminated polystyrene Graphene

Fig. 13. Phase transfer of reduced graphene from the aqueous phase to the organic phase via PS- $\mathrm{NH}_{2}$ functionalization. (a) Before sonication. Dark phases $=$ aqueous dispersions of reduced graphene; transparent phases $=\mathrm{PS}-\mathrm{NH}_{2}$ dissolved in organic solvents. (b) After $5 \mathrm{~h}$ sonication. Phase transfer occurred. (c) Schematic illustration of phase transfer via noncovalent functionalization (Reprinted with permission of The Royal Society of Chemistry, 2010).

Recently, graphene was also non-covalently modified with a conducting polymer, sulfonated polyaniline (SPANI) (Bai et al. 2009). SPANI, is soluble in water in neutral or alkaline media. Here it was expected that SPANI dispersed graphene sheets via $\pi-\pi$ interactions resembling a surfactant-assisted solubilisation, since SPANI can be considered a surfactant with a hydrophobic aromatic main chain and hydrophilic pendant sulfonate groups. GO was reduced in an aqueous solution of SPANI to give a homogeneous stable black dispersion. The SPANI-r-GO nanocomposites showed improved electrochemical stability and enhanced electrocatalytic activity.

The idea of using a polymeric surfactant to induce the solubility of graphene emerges as an interesting alternative. The dispersion of graphene within soluble polymeric matrices is fundamental for practical applications since it combines the superlative properties of both components. Polymer-dispersed graphene films can find applications as flexible conductors, transparent conductive coatings for optoelectronic devices, and/or photonics materials. A polymeric surfactant has been prepared by covalent attachment of a perylene derivative, $\mathrm{N}$ (carboxyphenyl)- $N^{\prime}$-(8-pentadecyl)perylene-3,4:9,10-bis(dicarboximide) (PDI-COOH), to PVA through esterification (Salavagione et al. 2010). The perylenediimide (PDI)-modified PVA polymers were soluble in water and DMSO. This solubility was conferred to the insoluble perylene derivative by the water-soluble polymer. This polymeric surfactant has been employed to induce the water solubility of graphene (Salavagione et al. 2011) giving a 
stable graphene dispersion. The presence of dispersed few layer graphene sheets was demonstrated by UV-visible, Raman and Fluorescence spectroscopy, and indirect evidence for the strong interaction between the perylene and the graphene was obtained from the analysis of polymer parameters, such as the crystallinity that completely disappeared and the remarkable decrease in segmental motion reflected by a shift of upto $70{ }^{\circ} \mathrm{C}$ in the $\mathrm{T}_{\mathrm{g}}$. In addition, the graphene used in this study was obtained by reductive intercalation and microwave assisted expansion of graphite (Morales et al, 2010). This method did not use rGO and avoided the creation of specific amounts of defects worsening the properties of graphene. To date the use of a polymeric surfactant has not been extensively studied and may be interesting to pursue this route for the preparation of graphene nanocomposites in the near future.

Although we have addressed many representative examples, this chapter is by far comprehensive, and works on other polymers such as polyethylene therephthalate (PET) (Zhang et al. 2010), polcarbonate (PC) (Kim and Macosko, 2009), poly(vinilydene fluoride)(PVDF) (Ansari and Giannelis, 2009) and poly(3,4-ethyldioxythiophene) (Xu et al. 2009), for example, can also be found in the literature.

\section{Conclusions}

Graphene is a cheap and multifunctional material that improves electrical, thermal, mechanical, optical, and gas barrier properties of polymer matrices, reuniting the laminar properties of layered silicates with the unique characteristics of carbon nanotubes. At very low filler contents most of these properties were better for graphene than those observed for other carbon-based reinforced nanocomposites due to the higher aspect ratio of graphene.

The versatility of graphene polymer nanocomposites suggests their potential application in automotive, electronics, aerospace and packaging. However the development and applicability of graphene-based PNCs will be intimately related to the limitations of graphene such as the lack of effective methods for scalable graphene production, which translates as higher costs, difficult manipulation of graphene sheets in processing due to its extremely low bulk density, and the lack of local sites or tensioned bonds on the graphene sheets to anchor functional moieties to make it more processable and compatible with other materials. In fact, so far only research on polymer nanocomposites using defect rich GO but not intact graphene itself have been published. Clearly the main drawback of GO is the disruption of the $\mathrm{sp}^{2}$ network that can transform it into a completely insulating material. The $\mathrm{sp}^{2}$ network is not totally recovered after thermal or chemical reduction since irreversible $\mathrm{sp}^{3}$ defects are created under strongly oxidizing conditions, worsening the final properties of graphene. In fact, an alternative to modified graphene involves the modification by diazonium salts, but, usually diazonium salts are reacted with expandable graphite, by thermal expansion of GO. Therefore, efforts have to be made in the functionalization of pristine graphene and/or expanded graphite obtained avoiding the oxidation step for polymer nanocomposites in order to obtain materials with higher performance.

As described before, numerous efforts to prepare useful graphene-based nanocomposites have been made and important improvements achieved. However, in spite of the considerable advances, excitement and promise of exfoliated graphene-based polymeric 
nanocomposites, substantial fundamental research is still necessary to provide a basic understanding of these materials to enable full exploitation of their nanoengineering potential. Despite the large number of combinations of matrices and potential reinforcing nano-elements with different chemistry, size, shape and properties, all graphene-based nanocomposites share common features with regard to fabrication methodologies, processing, morphology characterization and fundamental physics.

Thus, the key to prepare advanced graphene-based nanocomposites is the engineering at the polymer-graphene interface. Usually surfactant molecules have been employed to improve interface interactions. Developing an understanding of the characteristics of this interphase region, its dependence on the graphene surface chemistry, the relative arrangement of constituents and its relationship to the nanocomposite properties is a current research frontier in nanocomposites that unites the interest of scientists in physical chemistry, materials science and engineering. In the very near future, it is expected that a large number of new graphene-based nanocomposites using different polymer hosts (thermoplastic, thermosetting, and especially commodity polymers) and a wide range of graphene nanoelements (with different functionalities, size and shape) will be published. For instance the imaginative molecular design of polymeric surfactants has not yet been explored, and can circumvent the problem of solubility, dispersion in polymers and the film forming ability of graphene.

However, we are far from the end of the tunnel in terms of understanding the mechanisms of the enhancement effect in graphene nanocomposites. Thus, the challenge to reach the "graphene age" continues...

\section{References}

Ajayan, P. M. (2000). Single-walled carbon nanotube-polymer composites: Strength and weakness. Advanced Materials, vol. 12, No.10, (May 2000) 750-753, ISSN: 0935-9648.

Ansari, S. (2009). Functionalized graphene sheet-poly(vinylidene fluoride) conductive nanocomposites. Journal of Polymer Science Part B: Polymer Physics, Vol. 47, No. 9 (May 2009) 888-897, ISSN: 0887-6266.

Ansari, S. (2010). Oriented Arrays of Graphene in a Polymer Matrix by in situ Reduction of Graphite Oxide Nanosheets. Small, Vol. 6, No. 2, (January 2010) 205-209, ISSN: 1613-6810.

Baekland, L. H. (1909). The synthesis, constitution, and uses of bakelite. Journal of Industrial and Engineering Chemistry-US, Vol. 1 (March 1909) 149-161, ISSN: 0095-9014

Bai, H. (2009). Non-covalent functionalization of graphene sheets by sulfonated polyaniline. Chemical Communications, Vol. 45, No. 13, (April 2009), 1667-1669, ISSN: 1359-7345

Bai, H. (2010). A pH-sensitive graphene oxide composite hydrogel. Chemical Communications, Vol. 46, No. 14, (April 2010) 2376-2378, ISSN: 1359-7345.

Bao, Q. (2010). Graphene-Polymer Nanofiber Membrane for Ultrafast Photonics. Advanced Functional Materials, vol. 20, No. 5, (March 2010) 782-791, ISSN: 1616-301X.

Choi, E. (2010). Noncovalent functionalization of graphene with end-functional polymers. Journal of Materials Chemistry, Vol. 20, No 10, (March 2010) 1907-1912, ISSN: 09599428. 
Dreyer, D. R. (2010). The chemistry of graphene oxide. Chemical Society Reviews, Vol. 39, No. 1, (January 2010) 228-240, ISSN: 0306-0012 .

$\mathrm{Du}$, X. S. (2005). Direct synthesis of poly(arylenedisulfide)/carbon nanosheet composites via the oxidation with graphite oxide. Carbon, Vol 43, No 1, (January 2005) 195-213, ISSN: 0008-6223.

Eda, G. (2009). Graphene-based Composite Thin Films for Electronics. Nano Letters, Vol. 9, No 2, (February 2009) 814-818, ISSN: 1530-6984.

Eda, G. (2009). Transparent and conducting electrodes for organic electronics from reduced graphene oxide. Applied Phisics Letters, Vol 92, No. 23, (June 2008) 23305-1-23305-3, ISSN: 0003-6951.

Fang, M. (2009). Covalent polymer functionalization of graphene nanosheets and mechanical properties of composites. Journal of Materials Chemistry, Vol. 19, No. 38, (October 2009) 7098-7105, ISSN: 0959-9428.

Fang, M. (2010). Single-layer graphene nanosheets with controlled grafting of polymer chains. Journal of Materials Chemistry, Vol. 20, No. 10, (March 2010) 1982-1992, ISSN: 0959-9428.

Geim, A. K. (2007). The rise of graphene. Nature Materials, Vol. 6, No 3, (March 2007) 183191, ISSN: 1476-1122.

Huang, Y. (2010). Polypropylene/Graphene Oxide Nanocomposites Prepared by In Situ Ziegler-Natta Polymerization. Chemistry of Materials, Vol. 22, No. 13, (July 2010) 4096-4102, ISSN: 0897-4756.

Jang, J. (2009). Graphite oxide/poly(methyl methacrylate) nanocomposites prepared by a novel method utilizing macroazoinitiator. Composites Science and Technology, Vol. 69, No. 2, (February 2009) 186-191, ISSN: 0266-3538.

Kim, H. (2009). Processing-property relationships of polycarbonate/graphene nanocomposites. Polymer, Vol. 50, No. 3, (January 2009) 797-809, ISSN:0032-3861

Kim, H. (2010). Graphene/Polyurethane Nanocomposites for Improved Gas Barrier and Electrical Conductivityl. Chemistry of Materials, Vol. 22, No. 11, (June 2010) 34413450, ISSN: 0897-4756.

Kim, T. (2010). Synthesis of Phase Transferable Graphene Sheets Using Ionic Liquid Polymers. ACS Nano, Vol. 4, No. 3 (March 2010) • 1612-1618, ISSN: 1936-0851.

Krueger, A. (2010). Carbon Materials and Nanotechnology, Wiley-VCH, ISBN: 978-3-527-318032, Weinheim.

Lee, Y. R. (2009). Properties of Waterborne Polyurethane/Functionalized Graphene Sheet Nanocomposites Prepared by an in situ Method. Macromolecular Chemistry and Phisics, Vol. 210, No. 15, (August 2009) 1247-1254, ISSN: 1521-3935.

$\mathrm{Li}$, M. B. (2008). Processable aqueous dispersions of graphene nanosheets. Nature Nanotechnology. Vol. 3, No. 2, (February 2008) 101-105, ISSN : 1748-3387.

Li, G. L. (2010). Organo- and Water-Dispersible Graphene Oxide-Polymer Nanosheets for Organic Electronic Memory and Gold Nanocomposites. The Journal of Physical Chemistry C, Vol. 114, No. 29, (June 2010) 12742-12748, ISSN 1932-7447.

Liang, J. (2009) Infrared-Triggered Actuators from Graphene-Based Nanocomposites. The Journal of Physical Chemistry C, Vol. 113, No. 22, (June 2009) 9921-9924, ISSN 19327447. 
Liang, J. (2009). Molecular-level dispersion of graphene into poly(vinyl alcohol) and effective reinforcement of their nanocomposites. Advanced Functional Materials, Vol. 19, No. 14, (July 2009) 2297-2302, ISSN: 1616-301X.

Liu, P. (2000). Preparation and characterization of poly(vinyl acetate)-intercalated graphite oxide nanocomposite. Journal of Materials Chemistry, Vol. 10, No. 4, (February 2000) 933-935, ISSN: 0959-9428.

Liu, J. (2010). Synthesis, characterization, and multilayer assembly of pH sensitive graphenepolymer nanocomposites. Langmuir, Vol. 26, No. 12, (June 2010) 10068-10075, ISSN: 0743-7463.

Loh, K. P. (2010). The chemistry of graphene. Journal of Materials Chemistry, Vol. 20, No 12, (March 2010) 2277-2289, ISSN: 0959-942.

Morales, G. M. (2010). High-Quality Few Layer Graphene Produced by Electrochemical Intercalation and Microwave-Assisted Expansion of Graphite. Unpublished results.

Novoselov, K. S. (2004). Electric Field Effect in Atomically Thin Carbon Films". Science, Vol. 306, No 5696 (October 2004) 666-669, ISSN: 0036-8075

Ramanathan, T. (2007). Journal of Polymer Science Part B: Polymer Physics, Vol. 45, No. 11 (June 2007) 2097-2112, ISSN: 0887-6266.

Ramanathan, T. (2008). Functionalized graphene sheets for polymer nanocomposites. Nature Nanotechnology, Vol. 3, No. 6, (June 2008) 327-331, ISSN: 1748-3387.

Ray, S. S. (2003). Polymer/layered silicate nanocomposites: a review from preparation to processing. Progress in Polymer Science, Vol. 28, No. 11, (November 2003) 1539-1641, ISSN: 0079-6700.

Salavagione, H. J. (2009). Synthesis of poly(vinyl alcohol)/reduced graphite oxide nanocomposites with improved thermal and electrical properties. Journal of Materials Chemistry, Vol. 19, No. 28, (July 2009) 5027-5032, ISSN: 0959-9428.

Salavagione, H. J. (2009) Polymeric Modification of Graphene through Esterification of Graphite Oxide and Poly(vinyl alcohol). Macromolecules, Vol. 42, No. 17 (September 2009) 6331-6334, ISSN: 0024-9297.

Salavagione, H. J. (2010). Synthesis of water-soluble perylenediimide-functionalized polymer through esterification with poly(vinyl alcohol). Journal of Polymer Science A: Polymer Chemistry, Vol. 48, No. 16, (August 2010) 3613-3622, ISSN: 1099-0518.

Salavagione H. J (2010). Functionalization of multi-walled carbon nanotubes by stereoselective nucleophilic substitution on PVC. Macromolecules, Vol. 43, No. 23 (December 2010) 9754-9760, ISSN: 0024-9297

Salavagione, H. J. (2011). Graphene Water Dispersions Induced by a Conjugate DyeModified Polymer Surfactant. . Unpublished results.

Salavagione, H. J. (2011).When covalent linkages are essential to prepare effective reduced graphene oxide-based nanocomposites. The case of Poly(vinyl chloride). Unpublished results 2011.

Shaffer, M. S. P. (1999). Fabrication and characterization of carbon nanotube/poly(vinyl alcohol) composites. Advanced Materials, Vol. 11, No. 11, (August 1999) 937-941, ISSN: 0935-9648

Stankovich, S. (2006). Graphene-based composite materials. Nature, Vol. 442, No. 7100, (July 2006) 282 -286, ISSN: 0028-0836. 
Stankovich, S. (2006). Synthesis and exfoliation of isocyanate-treated graphene oxide nanoplatelets. Carbon, Vol. 44, No. 15, (December 2006) 3342-3347, ISSN: 0008-6223.

Sun, X. M. (2008). Nano-Graphene Oxide for Cellular Imaging and Drug Delivery. Nano Research, Vol. 1, No. 3, (September 2008) 203-212, ISSN: 1998-0124.

Thostenson, E. T. (2001). Advances in the science and technology of carbon nanotubes and their composites: a review. Composites Science and Technology, Vol. 61, No. 13, (October 2001) 1899-1912, ISSN: 0266-3538.

Verdejo, R. (2008). Functionalized graphene sheet filled silicone foam nanocomposites. Journal of Materials Chemistry, Vol. 18, No. 19, (May 2008) 2221-2226, ISSN: 09599428.

Vickery, J. L. (2009). Fabrication of Graphene-Polymer Nanocomposites With Higher-Order Three-Dimensional Architectures. Advanced Materials, Vol. 21, No. 21, (June 2009) 2180-2184, ISSN: 0935-9648.

Villar-Rodil, S. (2009). Preparation of graphene dispersions and graphene-polymer composites in organic media. Journal of Materials Chemistry, Vol. 19, No. 22, (June 2009) 3591-3593, ISSN: 0959-9428.

Wang, S. (2009). Thermal Expansion of Graphene Composites. Macromolecules, Vol. 42, No. 14, (July 2009) 5251-5255, ISSN: 0024-9297.

Wang, D. W. (2009). Fabrication of Graphene/Polyaniline Composite Paper via In Situ Anodic Electropolymerization for High-Performance Flexible Electrode. ACS Nano, Vol. 3, No. 7, (July 2009) 1745-1752, ISSN: 1936-0851.

$\mathrm{Xu}, \mathrm{Y}$. (2008). Flexible graphene films via the filtration of water-soluble noncovalent functionalized graphene sheets. Journal of the American Chemical Society, Vol. 130, No. 18, (May 2008) 5856-5857 ISSN: 0002-7863.

Xu, Y. F. (2009). A hybrid material of graphene and poly(3,4-ethyldioxythiophene) with high conductivity, flexibility, and transparency. Nano Research, Vol.2, No. 4, (April 2009) 343-348, ISSN: 1998-0124.

Yang, H. F. (2009). Convenient preparation of tunably loaded chemically converted graphene oxide/epoxy resin nanocomposites from graphene oxide sheets through two-phase extraction. Journal of Materials Chemistry, Vol. 19, No. 46, (December 2009) 8856-8860, ISSN: 0959-9428.

$\mathrm{Yu}, \mathrm{A}$. (2007). Graphite nanoplatelet-epoxy composite thermal interface materials. Journal of Physical Chemistry C, Vol. 111, No. 21 (May 2007) 7565-7569, ISSN: 1932-7447.

Zhang, B. (2010). Poly(N-vinylcarbazole) chemically modified graphene oxide. Journal of Polymer Science A: Polymer Chemistry, Vol. 48, No. 12, (June 2010) 2642-2649 ISSN: 1099-0518.

Zhang, H. B. (2010). Electrically conductive polyethylene terephthalate/graphene nanocomposites prepared by melt compounding. Polymer, Vol. 51, No. 5 , (March 2010) 1191-1196, ISSN: 0032-3861.

Zhang, K. Graphene/Polyaniline nanofiber composites as supercapacitor electrodes. Chemistry of Materials, Vol. 22, No. 4, (February 2010) 1392-1401, ISSN: 0897-4756.

Zhao, L. (2009). Polyaniline electrochromic devices with transparent graphene electrodes. Electrochimica Acta, Vol. 55, No. 2, (December 2009) 491-497, ISSN: 0013-4686. 
Zhao, X. (2010). Enhanced Mechanical Properties of Graphene-Based Poly(vinyl alcohol) Composites. Macromolecules, Vol. 43, No. 5, (March 2010) 2357-2363, ISSN: 00249297.

$\mathrm{Zu}$, S. Z. (2009). Aqueous dispersion of graphene sheets stabilized by pluronic copolymers: formation of supramolecular hydrogel. Journal of Physical Chemistry C, Vol. 113, No. 31, (August 2009) 13651-13657, ISSN: 1932-7447. 


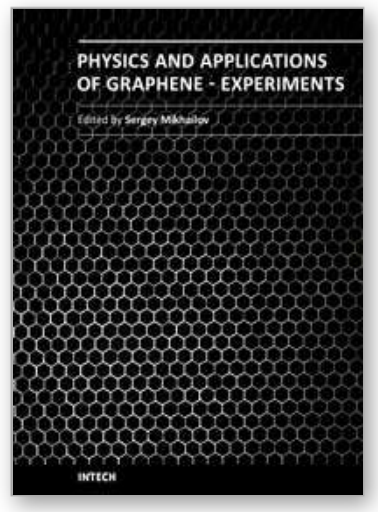

\author{
Physics and Applications of Graphene - Experiments \\ Edited by Dr. Sergey Mikhailov
}

ISBN 978-953-307-217-3

Hard cover, 540 pages

Publisher InTech

Published online 19, April, 2011

Published in print edition April, 2011

The Stone Age, the Bronze Age, the Iron Age... Every global epoch in the history of the mankind is characterized by materials used in it. In 2004 a new era in material science was opened: the era of graphene or, more generally, of two-dimensional materials. Graphene is the strongest and the most stretchable known material, it has the record thermal conductivity and the very high mobility of charge carriers. It demonstrates many interesting fundamental physical effects and promises a lot of applications, among which are conductive ink, terahertz transistors, ultrafast photodetectors and bendable touch screens. In 2010 Andre Geim and Konstantin Novoselov were awarded the Nobel Prize in Physics "for groundbreaking experiments regarding the two-dimensional material graphene". The two volumes Physics and Applications of Graphene - Experiments and Physics and Applications of Graphene - Theory contain a collection of research articles reporting on different aspects of experimental and theoretical studies of this new material.

\title{
How to reference
}

In order to correctly reference this scholarly work, feel free to copy and paste the following:

Horacio J. Salavagione, Gerardo Martinez and Gary Ellis (2011). Graphene-Based Polymer Nanocomposites, Physics and Applications of Graphene - Experiments, Dr. Sergey Mikhailov (Ed.), ISBN: 978-953-307-217-3, InTech, Available from: http://www.intechopen.com/books/physics-and-applications-of-grapheneexperiments/graphene-based-polymer-nanocomposites

\section{INTECH}

open science | open minds

\section{InTech Europe}

University Campus STeP Ri

Slavka Krautzeka 83/A

51000 Rijeka, Croatia

Phone: +385 (51) 770447

Fax: +385 (51) 686166

www.intechopen.com

\section{InTech China}

Unit 405, Office Block, Hotel Equatorial Shanghai

No.65, Yan An Road (West), Shanghai, 200040, China

中国上海市延安西路65号上海国际贵都大饭店办公楼 405 单元

Phone: +86-21-62489820

Fax: $+86-21-62489821$ 
(C) 2011 The Author(s). Licensee IntechOpen. This chapter is distributed under the terms of the Creative Commons Attribution-NonCommercialShareAlike-3.0 License, which permits use, distribution and reproduction for non-commercial purposes, provided the original is properly cited and derivative works building on this content are distributed under the same license. 